\title{
Genetic differences in alcohol sensitivity and the inheritance of alcoholism risk
}

\author{
A. C. HEATH, ${ }^{1}$ P. A. F. MADDEN, K. K. BUCHOLZ, S. H. DINWIDDIE, W. S. SLUTSKE, \\ L. J. BIERUT, J. W. ROHRBAUGH, D. J. STATHAM, M. P. DUNNE, J. B. WHITFIELD \\ AND N. G. MARTIN \\ From the Department of Psychiatry, Washington University School of Medicine, St. Louis and Department of \\ Psychology, University of Missouri, Columbia, MO, and Department of Psychiatry, Chicago Medical School, \\ North Chicago, IL, USA; and Department of Epidemiology and Population Health, Queensland Institute of \\ Medical Research and Department of Epidemiology, Queensland University of Technology, Brisbane, \\ Queensland, and Department of Clinical Biochemistry, Royal Prince Alfred Hospital, Sydney, New South \\ Wales, Australia
}

\begin{abstract}
Background. Substantial evidence exists for an important genetic contribution to alcohol dependence risk in women and men. It has been suggested that genetically determined differences in alcohol sensitivity may represent one pathway by which an increase in alcohol dependence risk occurs.
\end{abstract}

Methods. Telephone interview follow-up data were obtained on twins from male, female and unlikesex twin pairs who had participated in an alcohol challenge study in 1979-81, as well as other pairs from the same Australian twin panel surveyed by mail in 1980-82.

Results. At follow-up, alcohol challenge men did not differ from other male twins from the same age cohort on measures of lifetime psychopathology or drinking habits; but alcohol challenge women were on average heavier drinkers than other women. A composite alcohol sensitivity measure, combining subjective intoxication and increase in body-sway after alcohol challenge in 1979-81, exhibited high heritability $(60 \%)$. Parental alcoholism history was weakly associated with decreased alcohol sensitivity in women, but not after adjustment for baseline drinking history, or in men. High alcohol sensitivity in men was associated with substantially reduced alcohol dependence risk $(\mathrm{OR}=0.05,95 \% \mathrm{CI} 0 \cdot 01-0 \cdot 39)$. Furthermore, significantly decreased (i.e. low) alcohol sensitivity was observed in non-alcoholic males whose MZ co-twin had a history of alcohol dependence, compared to other non-alcoholics. These associations remained significant in conservative analyses that controlled for respondents' alcohol consumption levels and alcohol problems in 1979-81.

Conclusions. Men (but not women) at increased genetic risk of alcohol dependence (assessed by MZ co-twin's history of alcohol dependence) exhibited reduced alcohol sensitivity. Associations with parental alcoholism were inconsistent.

\section{INTRODUCTION}

Twin and adoption studies provide compelling evidence for an important genetic contribution to alcohol dependence risk (AlcD) in populations of predominantly European ancestry both in men (reviewed in McGue, 1994; Heath, 1995; Heath et al. 1997 a) and in women (Heath, 1995; Heath et al. 1997b). Emerging positive findings

\footnotetext{
1 Address for correspondence: Dr Andrew C. Heath. 40 North Kingshighway. Suite. 1. St. Louis, MO 63108. USA.
}

in linkage studies of alcohol dependence in men and women (Long et al. 1998; Reich et al. 1998). and genetic association studies (e.g. Whitfield $e t$ al. 1998) also suggest genetic influences. Considerably less progress has been made in delineating the mechanisms by which genetic differences between individuals ultimately give rise to differences in AlcD risk.

History of major depression, which is known to exhibit substantial co-morbidity with alcohol dependence (Regier et al. 1990; Kessler et al. 
1996) has been found to be significantly but only moderately genetically correlated with alcoholism risk (Kendler et al. 1993, 1995). Childhood conduct problems, or adult antisocial behaviour, which exhibit even stronger associations with alcohol dependence (Regier et al. 1990; Kessler et al. 1996) have been found to be significantly genetically correlated with alcohol dependence in some (Grove et al. 1990; Pickens et al. 1995; Slutske et al. 1998) but not all (True et al. 1999) twin studies that have examined this issue, but findings from adoption studies have generally been negative (Schulsinger, 1972; Goodwin et al. 1973; Crowe, 1974; Cadoret et al. 1985, 1987), perhaps because of the reduced power of detecting genetic correlations in the adoption compared with the twin design. It does not appear that history of depression and conduct problems entirely accounts for genetic influences on alcoholism risk. In analyses of alcoholism data from a large interview survey of the Australian twin panel, the alcoholism history of the respondent's $M Z$ co-twin remained a powerful predictor even when history of depression, childhood conduct disorder, and various personality and sociodemographic measures were controlled for, implying that much of the genetic influence on alcoholism risk could not be explained by co-morbid psychopathology or personality differences (Heath et al. 1997b). Known polymorphisms at the alcohol dehydrogenase $\mathrm{ADH} 2$ and $\mathrm{ADH} 3$ loci were found to account for a relatively small proportion of the total variance in alcohol problem and alcohol consumption measures in a subsample from this same panel (Whitfield et al. 1998), suggesting that other important sources of genetic variation remain to be detected.

Schuckit has argued that innate differences in alcohol sensitivity, operationalized as differences in response to a challenge dose of alcohol (including subjective intoxication (Schuckit, $1984 a$ ); static ataxia (Schuckit, 1985) and hormonal measures (Schuckit, 1984b)) may be predictors of increased alcoholism risk. Consistent with this hypothesis, adult offspring of alcoholics have generally been found to give lower ratings of intoxication after alcohol challenge than controls (Pollock, 1992) and have usually (Lipscomb et al. 1979; Hegedus et al. 1984; Lex et al. 1988; McCaul et al. 1991) but not always (Behar et al. 1983; O'Malley \&
Maisto, 1985; Nagoshi \& Wilson, 1987; Bauer \& Hesselbrock, 1993) been found to differ in amount of increase in body-sway, though the direction of effect has not always been consistent across studies of body-sway. Also consistent with this hypothesis, long-term follow-up of male alcohol challenge participants has found increased rates of alcohol dependence among those with low initial alcohol sensitivity (Schuckit \& Smith, 1996). Direct evidence from twin and adoption studies that these measures of alcohol response are in part under genetic control is somewhat meager, though results from the Australian Alcohol Challenge Twin Study (AACTS) (Martin et al. 1985a,b) confirm genetic influences on post-alcohol increase in body-sway (Martin et al. 1985b; Heath \& Martin, 1992) and subjective intoxication rating (Neale \& Martin, 1989; Heath \& Martin, 1992). To our knowledge, the question of whether such differences in alcohol sensitivity do indeed mediate genetic influences on alcohol dependence risk has not previously been directly examined using the design than can provide the most powerful test of this hypothesis, the classical twin design. In addition, much of the existing literature on alcohol challenge performance has been gathered only in male subjects. Here we address the question of whether differences in alcohol sensitivity are genetically correlated with AlcD risk, in both women and men, using data from a follow-up interview survey of the Australian twin panel (Heath et al. 1997b), that included twins who participated in AACTS. Unusually, for such an early study, AACTS included approximately equal numbers of men and women. Because information about alcohol dehydrogenase genotypes (ADH2 and $\mathrm{ADH} 3)$ are also available for this sample (Whitfield et al. 1998), we also assess whether polymorphisms at these loci contribute significantly to differences in alcohol sensitivity.

\section{METHOD}

\section{Sample}

Participants were twins from a volunteer adult twin register, formed in 1978-9 and maintained by the Australian National Health and Medical Research Council (NH\&MRC). Almost all were of European ancestry. In 1979-81, 206 young adult twin pairs born $1944-63$ had participated 
in an alcohol challenge study (Martin et al. $1985 a, b$ ), including 45 monozygotic (MZ) female, $43 \mathrm{MZ}$ male, $42 \mathrm{DZ}$ female, $37 \mathrm{DZ}$ male and $39 \mathrm{DZ}$ unlike-sex pairs. Approximately equal numbers of women $(N=213)$ and men $(N=199)$ were tested. Additional data on this sample were obtained in a mailed questionnaire survey of the entire adult twin panel conducted in 1980-82, with responses from 132 complete pairs and 16 single twins from participants in the alcohol challenge study (Jardine et al. 1984; Kendler et al. 1986), and in a telephone interview follow-up in 1992-3 (Heath et al. 1997b). At interview follow-up, data were obtained from 187 women ( $87 \cdot 4 \%$ response rate) and 162 men $(81.4 \%)$. An additional five subjects were deceased, seven subjects were overseas and could not be reached, and 28 subjects were not contacted because they either could not be located or had previously requested that they not be contacted for further research studies. Excluding these cases, the cooperation rate in the interview follow-up was $95.4 \%$ for women and $90.1 \%$ in men.

In addition to participants in the alcohol challenge study, an additional 3676 complete twin pairs and 551 single twins from the NH\&MRC twin panel, born 1893-1964, responded to the 1980-2 questionnaire survey. In the 1992-3 survey, follow-up interviews were completed with 3659 of these women and 1879 men (respectively $88.3 \%$ and $82.5 \%$ of those eligible for follow-up (Heath et al. 1997b)). Comparisons of the subset of these subjects born 1944-63 (2628 women, 1584 men) with the alcohol challenge $(\mathrm{AC})$ participants were used to identify correlates of willingness to participate in the alcohol challenge study, and thus provide a check on the generalizability of findings from the AC sample.

\section{Assessments}

Participants in the Australian Alcohol Challenge Twin Study (AACTS) received baseline questionnaire assessments of drinking history, personality and sociodemographic variables, and baseline and post-alcohol $(0.75 \mathrm{~g}$ ethanol $/ \mathrm{kg}$ body weight) assessments of subjective intoxication (rated on a 10-point scale where $1=$ completely sober, $10=$ most drunk the respondent has ever been, and rescaled by dividing by 10 ), static ataxia assessed both with eyes open and eyes closed, and other measures of psychomotor coordination (Martin et al. $1985 b$; Neale \& Martin, 1989; Heath \& Martin, 1992). Guided by the work of Schuckit \& Smith (1996), analyses of associations with alcohol dependence risk focused on subjective ratings of intoxication and static ataxia measures, using data from the first round of post-alcohol testing, beginning $20 \mathrm{~min}$ after dosing. To quantify change in body-sway, regression residuals were estimated from a regression equation predicting post-alcohol body-sway from pre-alcohol sway scores (Nagoshi \& Wilson, 1987), and a quadratic power transformation was used to reduce skewness and kurtosis. As presented here, low scores indicate a smaller increase in body-sway after alcohol challenge (i.e. low sensitivity to alcohol). Principal component analysis of the subjective intoxication rating and static ataxia residual scores was used to generate 'alcohol sensitivity' component scores. Loadings on the first principal component of the subjective intoxication and eyes open and eyes closed ataxia measures were $0.40,0.64$ and 0.65 in women, and 0.49, 0.61 and 0.62 in men. The first principal component accounted for $61 \%$ of the variance in these variables in both women and men.

Included in the AACTS baseline questionnaire were limited drinking history questions that included measures of heavy drinking (number of drinks per typical drinking occasion, scaled as (0) $1-2$; (1) $3-5$; (2) 6-8; and (3) $\geqslant 9$ ), excessive drinking (drinking more than the respondent felt was good for him/her), morning drinking, frequency of being drunk, and frequency of being hungover (these two latter with response categories never, sometimes or often). Responses to these five items were summed to yield a baseline problem drinking score with value ranging from $0-15$. Quantity and frequency measures of typical weekly alcohol consumption were obtained, from which total weekly alcohol consumption in standard drinks was computed, and log-transformed. In this early study no attempt was made at baseline to assess family history of alcoholism, nor to exclude subjects reporting a personal history of alcohol problems.

Follow-up assessments in 1992-3 included global ratings of maternal and paternal alcohol problems (Slutske et al. 1996), as well as DSMIII-R assessments of history of AlcD, major 
depressive disorder (MDD) (DSM-IV diagnoses were derived for this variable), panic disorder, social phobia and adolescent conduct disorder (CD). These diagnostic assessments were adapted for telephone administration from the SemiStructured Assessment for the Genetics of Alcoholism (SSAGA) (Bucholz et al. 1994). A positive parental history of alcoholism was inferred if at least one twin reported parental alcohol problems. In addition, recent (12-month) quantity and frequency measures of alcohol use, as well as 12-month and lifetime estimates of the respondent's heaviest consumption in a single day, were obtained. All consumption measures were assessed in standard drinks.

As described elsewhere, ADH2 and ADH3 genotypes for 369 participants in the alcohol challenge study (176 male, 193 female) were typed either at the time of the interview followup, or at the time of a separate follow-up study of alcohol challenge participants (Whitfield et al. 1998): genotypes for ADH2 and ADH3 were determined using DNA extracted from white blood cells, using the polymerase chain reaction and restriction digestion, followed by electrophoresis of the polymerase chain reaction (PCR) products (von Wartburg et al. 1988; Xu et al. 1988). The only genotypes observed in the sample were $\mathrm{ADH} 2 * 1 / * 1$ and $* 1 / * 2$, and $\mathrm{ADH} 3$ $* 1 /{ }^{*} 1, * 1 /{ }^{*} 2$ and $* 2 / * 2$.

All participants in the original alcohol challenge study gave written informed consent. Implied consent procedures were followed with the 1981 questionnaire survey, a cover letter explaining the research and that participation was voluntary. All participants in the telephone interview survey gave verbal consent to participate in the research, after the elements of informed consent had been reviewed with them verbally.

\section{Statistical analyses}

Rates of psychopathology and heavy alcohol use were compared between the alcohol challenge and comparison samples by chi-square test. For these comparisons no adjustment was made for non-independence of observations on twin pairs, since in this case the overestimation of statistical significance would be conservative, i.e. would cause us to suspect sampling biases where none existed. To adjust for known differences at baseline between the alcohol challenge and comparison samples on sociodemographic and baseline alcohol consumption measures, results of unweighted analyses were compared to analyses using sampling weights to adjust for this volunteer bias effect (Rosenbaum \& Rubin, 1983; Heath et al. 1998). Twin-pair covariances were computed for alcohol sensitivity scores, and models allowing for additive and non-additive genetic and non-shared environmental influences were fitted to these data by maximum-likelihood using standard modelfitting methods (Neale \& Cardon, 1992; Neale, 1998). Associations between alcohol sensitivity scores and parental history of alcohol dependence, respondent's history of alcohol dependence, and co-twin's history of alcohol dependence, were assessed using the SAS (1990) GLM procedure. Post-hoc analyses predicting lifetime alcohol dependence as a function of low alcohol sensitivity $(<25 \%$ ile of the sex-specific distribution of alcohol sensitivity scores) or high alcohol sensitivity ( $>75 \%$ ile) or $\mathrm{ADH} 2$ or $\mathrm{ADH} 3$ genotypes, were conducted using logistic regression analysis. Most analyses are reported with and without adjustment for baseline covariates (baseline weekly alcohol consumption and alcohol problem measures): since differences in alcohol sensitivity may contribute to differences in alcohol dependence risk via effects on levels of alcohol consumption or excessive drinking, covariate adjustment must be considered a conservative procedure, which may cause us to underestimate the significance of findings. For critical analyses of associations with parental or own and co-twin's alcoholism history, bootstrapping (Efron \& Tibshirani, 1986) - randomly resampling the observed data with replacement, using the twin pair as the unit for resampling - was used to obtain empirical estimates of the standard errors of parameters, adjusted for the non-independence of observations on twin pairs (i.e. clustered sampling). In each case, 3000 bootstraps were run per analysis. Logistic regression analyses were conducted using STATA (Stata Corp., 1997) to obtain $95 \%$ confidence intervals that were corrected for clustered sampling. Other significance tests, which were not significant even without adjustment for correlated observations on twin pairs, are reported using the unadjusted test statistic, since correction for non-independence would only make this statistic even less signifi- 
cant. Where significant chi-squares were obtained, we used the conservative adjustment of dividing the chi-square by one-half, equivalent to assuming that observations on twin pairs were perfectly correlated. Finally, bivariate genetic models (e.g. Neale \& Cardon, 1992; Kendler et al. 1993) were fitted to alcohol dependence symptom count and alcohol sensitivity score data, to quantify the magnitude of the genetic correlation between sensitivity score and dependence symptom count. For this final analyses, models were fitted to raw data by maximum likelihood, using all available data on alcohol dependence symptom count from male and female twins born 1944-63, plus alcohol sensitivity data from male twins only (since no association was observed in female twins).

\section{RESULTS}

\section{Generalizability of sample}

Lifetime history of psychopathology, reported family history of alcohol problems, and current alcohol use of the AC and comparison samples, as assessed at interview follow-up, are summarized in Table 1. While male AC participants appeared to be representative, with respect to these measures, of all males from the same birth years on the Australian twin panel, this was not true for women. Among women, the lifetime prevalence of DSM-III-R AlcD was substantially higher among those who had volunteered for the AC study than among those who had not. There were also modestly increased rates of conduct disorder $(P=0.03)$ and of social phobia $(P=0.02)$ among the AC women. At the time of follow-up, $\mathrm{AC}$ women remained heavier drinkers on measures of high current frequency of alcohol use, number of drinks per drinking occasion, and maximum 1-day consumption in the preceding year, and lifetime maximum 1-day consumption was also higher. Male AC participants did not differ significantly from the comparison sample, though there was a trend for lower lifetime rates of psychopathology among male AC participants. Reported rates of parental alcohol problems did not differ significantly in either gender, nor when data were pooled across gender (not shown).

Despite the over representation of heavy drinkers among women AC participants, there was a wide range of levels of exposure to alcohol, as can be seen from Fig. 1. Fig. 1(a) summarizes the distribution of average weekly

Table 1. History of psychopathology and alcohol use at interview follow-up of the alcohol challenge and comparison samples (all differences are non-significant unless otherwise indicated)

\begin{tabular}{|c|c|c|c|c|}
\hline & \multicolumn{2}{|c|}{ Women } & \multicolumn{2}{|c|}{ Men } \\
\hline & $\begin{array}{c}\text { Alcohol } \\
\text { challenge } \\
(N=182-190) \\
\%\end{array}$ & $\begin{array}{c}\text { Comparison } \\
\text { sample } \\
(N=2452-2628) \\
\%\end{array}$ & $\begin{array}{c}\text { Alcohol } \\
\text { challenge } \\
(N=158-182) \\
\%\end{array}$ & $\begin{array}{c}\text { Comparison } \\
\text { sample } \\
(N=1421-1584) \\
\%\end{array}$ \\
\hline \multicolumn{5}{|l|}{ Psychopathology/family history } \\
\hline Childhood conduct disorder & $5 \cdot 4$ & $2 \cdot 7^{*}$ & $18 \cdot 0$ & $19 \cdot 3$ \\
\hline Alcohol dependence & $15 \cdot 3$ & $7 \cdot 0^{* * *}$ & $24 \cdot 1$ & $27 \cdot 5$ \\
\hline Major depression (DSM-IV) & $26 \cdot 2$ & $22 \cdot 2$ & $12 \cdot 4$ & $16 \cdot 9$ \\
\hline Panic disorder & $5 \cdot 4$ & $4 \cdot 4$ & 1.9 & $2 \cdot 4$ \\
\hline Social phobia & 4.9 & $2 \cdot 1^{*}$ & $1 \cdot 2$ & $2 \cdot 4$ \\
\hline Paternal alcohol problems & 26.9 & $23 \cdot 5$ & $25 \cdot 3$ & $21 \cdot 6$ \\
\hline Maternal alcohol problems & 7.9 & $5 \cdot 6$ & $5 \cdot 0$ & $4 \cdot 2$ \\
\hline Any parental alcohol problems & $30 \cdot 0$ & $27 \cdot 0$ & $28 \cdot 3$ & $24 \cdot 3$ \\
\hline \multicolumn{5}{|l|}{ Alcohol use } \\
\hline $\begin{array}{l}\text { Lifetime maximum consumption } / 24 \mathrm{~h} \\
(>10 \text { drinks in women } ;>25 \text { drinks in men })\end{array}$ & $28 \cdot 0$ & $20 \cdot 1^{*}$ & $20 \cdot 8$ & $17 \cdot 5$ \\
\hline $\begin{array}{l}\text { Current maximum consumption } / 24 \mathrm{~h} \\
(>6 \text { drinks in women; }>10 \text { drinks in men })\end{array}$ & $20 \cdot 9$ & $13 \cdot 3 * *$ & $27 \cdot 2$ & $26 \cdot 3$ \\
\hline Frequency of alcohol use $\geqslant 3$ days/week & $31 \cdot 7$ & $20 \cdot 2^{* * *}$ & $41 \cdot 4$ & $36 \cdot 5$ \\
\hline $\begin{array}{l}\text { Drinks per drinking occasion } \\
\text { ( }>3 \text { drinks) }\end{array}$ & $13 \cdot 2$ & $11 \cdot 3^{* * *}$ & $34 \cdot 6$ & $29 \cdot 9$ \\
\hline
\end{tabular}

Diagnostic measures are based on DSM-III-R criteria, and alcohol-use measures are for preceding 12 months, unless otherwise noted Sample sizes for family history assessments include co-twin reports in cases where a subject was lost to follow-up.

${ }^{*} P<0.05 ;{ }^{* * *} P<0.001$ for comparisons between alcohol challenge and comparison samples. 
(a)

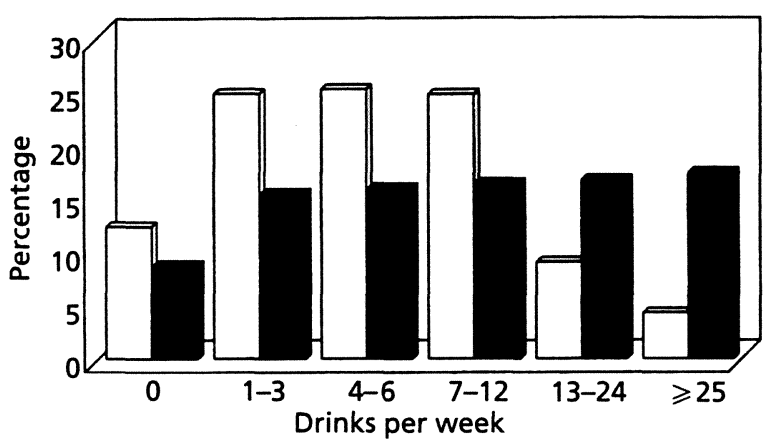

(b)

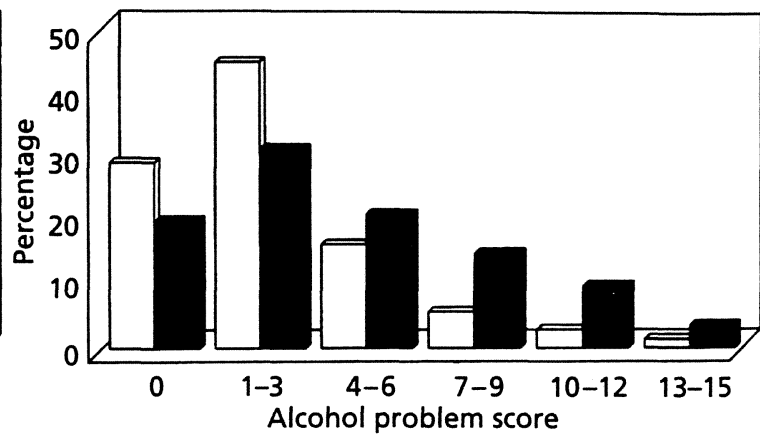

FIG. 1. Average drinks per week: $(a)$ and alcohol problem score; $(b)$ of alcohol challenge study participants at initial baseline assessment $(\square$, women; $\square$, men).

Table 2. Twin pair correlations for alcohol sensitivity component scores, for participants in the 1979-81 alcohol challenge study

\begin{tabular}{lccc}
\hline \hline Twin group & $N$ pairs* & $r$ & Weighted $r \dagger$ \\
\hline MZ female & 45 & 0.68 & 0.81 \\
MZ male & 43 & $0 \cdot 56$ & $0 \cdot 59$ \\
DZ female & 42 & 0.28 & $0 \cdot 40$ \\
DZ male & 37 & $0 \cdot 39$ & $0 \cdot 28$ \\
DZ unlike-sex & 39 & $0 \cdot 10$ & $0 \cdot 15$ \\
\hline
\end{tabular}

* Unweighted sample size.

$\dagger$ Weighted to adjust for volunteer bias with respect to participation in the alcohol challenge study, using twin-pair sampling weights generated separately for each zygosity group.

consumption of alcohol at baseline of the AC women and men. Fig. $1(b)$ summarizes the distribution of overall alcohol problem scores. Some $15.6 \%$ of these women (and $29.1 \%$ of men) reported that they felt that they drank too much, $13.7 \%(23.5 \%)$ reported taking six or more drinks per typical drinking occasion, $13.2 \%(19.0 \%)$ reported drinking daily or most days, and $8.0 \%(24.5 \%)$ reported that they often got drunk; but $24.3 \%$ of women $(23.0 \%$ of men) reported using alcohol no more than 100 times in their entire life (data not shown).

\section{Heritability of composite sensitivity measure}

Twin-pair correlations for the composite alcohol sensitivity principal component score are shown in Table 2 for all participants in the original AC study. Consistent with the prediction of an important genetic contribution to differences in alcohol sensitivity, MZ twin-pair correlations in each gender were substantially higher than the corresponding DZ correlations. A model that
Table 3. Association between alcohol sensitivity measures and parental alcoholism history in unweighted analyses. Tests of statistical significance used standard errors estimated by bootstrapping, to adjust for the non-independence of observations on twin pairs

\begin{tabular}{|c|c|c|c|c|}
\hline \multirow{3}{*}{$\begin{array}{l}\text { Parental alcohol } \\
\text { problems? } \\
N\end{array}$} & \multicolumn{2}{|c|}{ Women } & \multicolumn{2}{|c|}{ Men } \\
\hline & No & Yes & No & Yes \\
\hline & 133 & 57 & 131 & 51 \\
\hline $\begin{array}{l}\text { Alcohol sensitivity } \\
\text { score }\end{array}$ & $0 \cdot 12$ & $-0 \cdot 28^{*}$ & -0.07 & $0.03^{\text {xs }}$ \\
\hline Subjective intoxication & $0 \cdot 58$ & $0 \cdot 48^{*}$ & $0 \cdot 44$ & $0.44^{\mathrm{xis}}$ \\
\hline $\begin{array}{l}\text { Body-sway }{ }^{\dagger} \\
\text { Eyes-open }\end{array}$ & & $-1.10 \times 5$ & & \\
\hline Eyes-closed & $\begin{array}{l}-1.02 \\
-1.22\end{array}$ & $-1.30^{\mathrm{Ns}}$ & $\begin{array}{l}-1.02 \\
-1.23\end{array}$ & $-1.30^{* 5}$ \\
\hline
\end{tabular}

${ }^{*} P<0.05 ;{ }^{*} P=0.12 ;{ }^{\text {ss }} P>0.15$.

$\dagger$ Higher (i.e. less negative) scores correspond to a larger increase in body sway.

Means (and standard deviations) of alcohol sensitivity measures in females $(f)$ and males $(m)$ were: alcohol sensitivity $-f=0(1.61)$ $\mathrm{m}=0 \quad(1.58)$; subjective intoxication $-\mathrm{f}=0.55 \quad(0.28), \mathrm{m}=0.44$ $(0.30)$; eyes-open body-sway $-\mathrm{f}=-1.04(0.41), \mathrm{m}=-1.02(0.33)$ eyes-closed body-sway $-\mathrm{f}=-1.26(0.51), \mathrm{m}=-1.25(0.47)$.

allowed for only additive genetic and nonshared environmental contributions to variation in alcohol sensitivity scores gave an excellent fit to the observed data $\left(\chi^{2}=9 \cdot 09, \quad \mathrm{df}=13\right.$, $P=0.77)$, and yielded an overall estimate of the heritability of individual differences in alcohol sensitivity of $60 \%(95 \% \mathrm{CI} 46-70 \%)$. A model assuming no genetic influence on alcohol sensitivity in either gender could be rejected $\left(\chi^{2}=7.02, \mathrm{df}=2, P=0.03\right)$. Despite the trend in Table 2 for higher heritability in women than men, and for some sex-specific genetic effects, these effects were not significant $\left(\chi^{2}=1 \cdot 31\right.$, 
Table 4. Association between alcohol sensitivity measures and respondent's lifetime history of DMSIII-R alcohol dependence at interview follow-up in unweighted analyses. Tests of statistical significance used standard errors estimated by bootstrapping in order to correct for the non-independence of observations on twin pairs

\begin{tabular}{|c|c|c|c|c|}
\hline \multirow[b]{2}{*}{$\begin{array}{l}\text { History of alcohol dependence? } \\
N\end{array}$} & \multicolumn{2}{|c|}{ Women } & \multicolumn{2}{|c|}{ Men } \\
\hline & $\begin{array}{l}\text { No } \\
155\end{array}$ & $\begin{array}{l}\text { Yes } \\
28\end{array}$ & $\begin{array}{l}\text { No } \\
120\end{array}$ & $\begin{array}{l}\text { Yes } \\
38\end{array}$ \\
\hline \multicolumn{5}{|l|}{ Unadjusted scores } \\
\hline Alcohol sensitivity score & 0.09 & $-0 \cdot 18^{\mathrm{Ns}}$ & $0 \cdot 28$ & $-0.65^{* * *}$ \\
\hline Subjective intoxication & 0.57 & $0.50^{\mathrm{Ns}}$ & 0.49 & $0.33^{* *}$ \\
\hline \multicolumn{5}{|l|}{ Body-sway $\dagger$} \\
\hline Eyes-open & -1.03 & $-1.09^{\mathrm{Ns}}$ & -0.98 & $-1 \cdot 13^{* *}$ \\
\hline Eyes-closed & $-1 \cdot 22$ & $-1 \cdot 26^{\mathrm{Ns}}$ & $-1 \cdot 19$ & $-1 \cdot 40^{* *}$ \\
\hline \multicolumn{5}{|l|}{ Adjusted scores $\ddagger$} \\
\hline Alcohol sensitivity score & 0.05 & $0.09^{\mathrm{Ns}}$ & $0 \cdot 14$ & $-0.32^{*}$ \\
\hline Subjective intoxication & 0.56 & $0.56^{\mathrm{NS}}$ & 0.46 & $0.41^{\text {ss }}$ \\
\hline \multicolumn{5}{|l|}{ Body-swayt } \\
\hline Eyes-open & -1.04 & $-1.04^{\mathrm{Ns}}$ & -1.00 & $-1.09^{\times s}$ \\
\hline Eyes-closed & $-1 \cdot 23$ & $-1 \cdot 21^{\mathrm{NS}}$ & $-1 \cdot 22$ & $-1 \cdot 34^{x s}$ \\
\hline
\end{tabular}

"0.05 $<P<0.10 ;{ }^{* *} P<0.01 ; * * * P<0.001$

$\dagger$ Higher (i.e. less negative) scores correspond to a larger increase in body-sway.

$\ddagger$ Controlling for baseline alcohol problem score and average weekly alcohol consumption.

$\mathrm{df}=3, P=0 \cdot 73$ ). Using sampling weights to adjust for the under representation of light drinkers in the alcohol challenge sample, as well as for non-random sampling with respect to other sociodemographic variables, gave even stronger support for an important genetic influence on alcohol sensitivity in women, with an estimated $79 \%$ of the total variance being attributable to additive genetic influences, but did not change the heritability estimate in men $(57 \%)$. No association was found between either $\mathrm{ADH} 2$ or $\mathrm{ADH} 3$ genotype and alcohol sensitivity score either in women or in men (ADH2 genotype: unadjusted $F(1,190)=0.37, P>0.26$; $F(1,177)=0.42, P>0.5 ; \mathrm{ADH} 3$ genotype: unadjusted $F(2,190)=1.96, \quad P>0.14 ; \quad F(2,177)$ $=0.62, P>0.5)$ indicating that these polymorphisms at least could not explain the observed genetic influence.

\section{Sensitivity as a function of parental alcoholism}

Shown in Table 3 are summary alcohol sensitivity scores, and scores on the individual measures of subjective intoxication and static ataxia, as a function of parental (either paternal or maternal) alcoholism history. Women with a parental history of alcohol problems gave significantly lower ratings of subjective intoxication, and there was a non-significant trend
$(P=0 \cdot 12)$ for lower overall alcohol sensitivity scores. Neither of these effects was significant when baseline problem drinking and average weekly alcohol consumption scores were controlled for (unadjusted $t=0 \cdot 87, \mathrm{df}=1$, $P>0.39$; unadjusted $t=0.89, \mathrm{df}=1, P>0.37$ ), and this remained true when sampling weights were used to adjust for systematic sampling biases with respect to $\mathrm{AC}$ participation. More striking was the complete absence of any association with parental alcoholism in men. This remained true when baseline problem drinking score and average weekly alcohol consumption were controlled for; but in weighted analyses, with adjustment for nonindependence, significantly increased (not decreased) sensitivity was observed in males with a positive parental history of alcoholism, once baseline drinking and problem drinking were controlled for.

\section{Sensitivity and alcohol dependence history}

Table 4 summarizes the overall association between lifetime history of DSM-III-R AlcD at interview follow-up, and alcohol sensitivity scores. In women, no significant association was found in either unweighted or weighted analyses. In men, weighted and unweighted analyses gave consistent results. Using unadjusted scores, those 

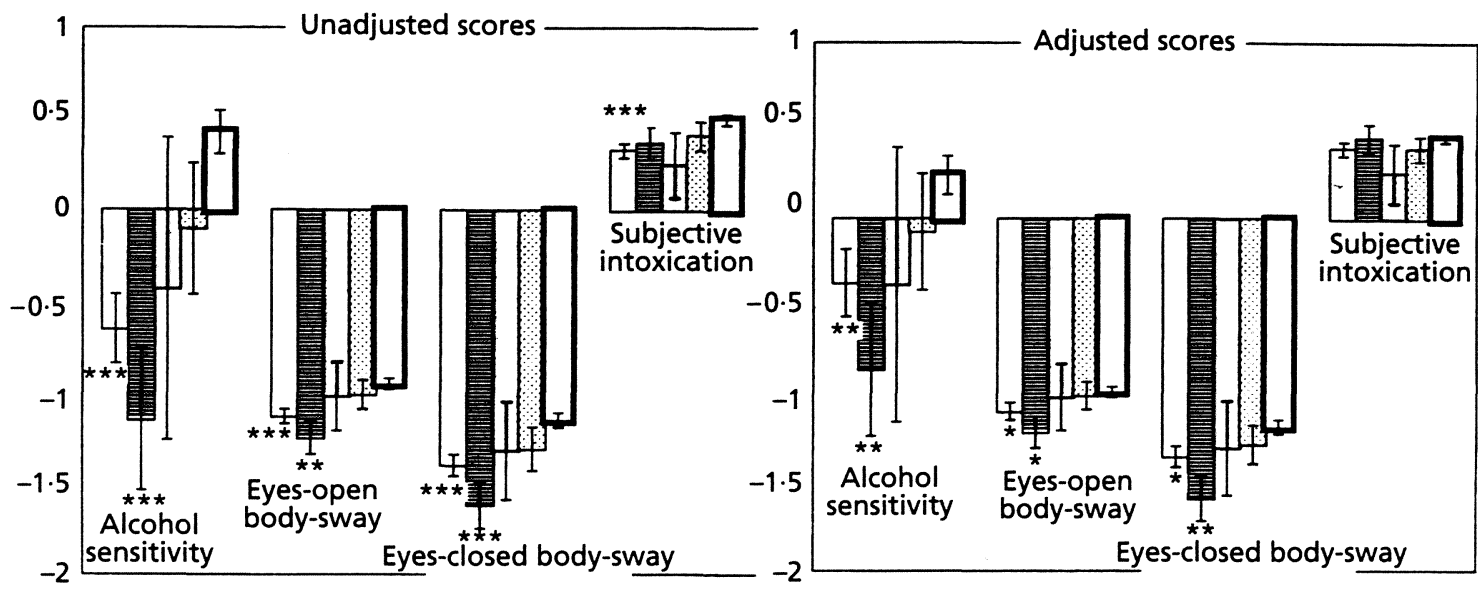

FIG. 2. Alcohol sensitivity scores as a function of participant's $(\square)$ and co-twin's (目, MZ; $\square, D Z$ female; $:$, DZ male) history of alcohol dependence. Error bars represent $95 \%$ confidence limits. All significance tests are compared to the group with both twins unaffected ( $\mathbf{0}$ ). Adjusted scores control for respondent's baseline alcohol problem score and average weekly alcohol consumption.

with a life-time history of alcohol dependence had significantly lower alcohol sensitivity scores, a consequence of both lower subjective ratings of intoxication, and a smaller increase in bodysway. When baseline alcohol problem and average weekly alcohol consumption scores were controlled for, none of these effects remained significant. However, all adjusted effects were in the predicted direction, and the association between alcohol dependence and alcohol sensitivity score was almost significant (unweighted analysis: adjusted $P=0.072$ ). Post-hoc analyses established that the association with AlcD was explained by the very low risk of alcohol dependence in males scoring in the top $25 \%$ of the distribution of alcohol sensitivity scores: compared to those scoring between the 25 th and 75 th percentiles, males scoring in the upper $25 \%$ had a substantially reduced risk of alcohol dependence $(\mathrm{OR}=0.05,95 \% \mathrm{CI}$ 0.01-0.39), with a similar though non-significant trend in females $(\mathrm{OR}=0.39$, 95\% CI $0 \cdot 14-1 \cdot 11)$; but males and females scoring in the bottom $25 \%$ did not show significantly increased risk (males, $\mathrm{OR}=0.98, \quad 95 \% \mathrm{CI} \quad 0.44-2 \cdot 19 ; \quad$ females, $\mathrm{OR}=1 \cdot 32,95 \% \mathrm{CI} 0 \cdot 60-2 \cdot 92)$. Controlling for baseline alcohol consumption and problem drinking score did not remove the association between high alcohol sensitivity and reduced alcohol dependence risk (males, $\mathrm{OR}=0 \cdot 10$, $95 \%$ CI $0.01-0.81$; females, OR $=0.42,95 \% \mathrm{CI}$ $0 \cdot 14-1 \cdot 26)$. There was no association in either gender between alcohol sensitivity score, or component measures, and lifetime history of major depression or conduct disorder $(P>0 \cdot 10$ in all cases, results not shown).

\section{Sensitivity and co-twin's dependence history}

Controlling for baseline alcohol consumption and alcohol problem scores could be viewed as a conservative procedure, since any effect on AlcD risk of differences in alcohol sensitivity may be in part mediated through effects on alcohol consumption patterns and associated problems at baseline. As an alternative approach, in Fig. 2 we compare alcohol sensitivity scores of male respondents with no reported history of AlcD, but who were either at high or intermediate genetic risk ( $\mathrm{MZ}$ or $\mathrm{DZ}$ co-twin had a history of AlcD) or low risk (no co-twin history of AlcD), with those of individuals with a history of AlcD. For overall alcohol sensitivity score, and for both measures of body-sway, in both unweighted and weighted analyses, compared to twins from pairs where neither had a history of AlcD, both alcohol dependent twins, and also the non-alcohol dependent MZ cotwins of alcohol dependent twins, had significantly lower scores. Furthermore, this finding remained significant in unweighted analyses (with a trend in the same direction in weighted analyses) even where the respondent's baseline alcohol consumption and alcohol problem scores were controlled for. Despite small sample size 
Table 5. Results of bivariate genetic analysis of alcohol dependence symptom count and alcohol sensitivity score in male twins. Estimates of genetic and non-shared environmental variance components and correlations, and their $95 \%$ confidence interval $(C I)$, are shown

\begin{tabular}{|c|c|c|c|c|}
\hline & \multicolumn{2}{|c|}{$\begin{array}{l}\text { Additive genetic } \\
\text { variance }\end{array}$} & \multicolumn{2}{|c|}{$\begin{array}{l}\text { Non-shared } \\
\text { environmental } \\
\text { variance }\end{array}$} \\
\hline & $\%$ & $95 \% \mathrm{CI}$ & $\%$ & $95 \% \mathrm{CI}$ \\
\hline $\begin{array}{l}\text { Alcohol dependence } \\
\text { symptom count }\end{array}$ & 48 & $(44-53)$ & 52 & $(47-56)$ \\
\hline \multirow{4}{*}{$\begin{array}{l}\text { Alcohol sensitivity } \\
\text { score }\end{array}$} & 56 & $(35-71)$ & 44 & $(29-65)$ \\
\hline & \multicolumn{2}{|c|}{ Correlation } & \multicolumn{2}{|c|}{ Correlation } \\
\hline & $r_{\mathrm{G}}$ & $95 \% \mathrm{CI}$ & $r_{\mathrm{E}}$ & $95 \% \mathrm{CI}$ \\
\hline & 0.72 & $(0.34-1.00)$ & 0.04 & $(0.00-0.37)$ \\
\hline
\end{tabular}

( $N=9$ pairs), there was a trend for males with no alcohol dependence history but an alcohol dependent $\mathrm{MZ}$ co-twin to be more likely to score in the lowest $25 \%$ on the distribution of alcohol sensitivity scores (OR $=3.75$, 95\% CI 0.45 $31 \cdot 13)$. No significant differences were observed in women, though the lowest sensitivity scores were again observed in the non-dependent $\mathrm{MZ}$ co-twins of AlcD women (not shown).

Of those males with high alcohol sensitivity, i.e. scoring in the upper $25 \%$ of the distribution of alcohol sensitivity scores, $94.7 \%$ were from concordant unaffected pairs, compared with $61.8 \%$ of males scoring on the 26th-50th percentile, $56.0 \%$ of males scoring on the 51 st -75 th percentile, and $44 \cdot 1 \%$ of males scoring above the $75 \%$ ile, a highly significant linear trend (adjusted chi-square $=10 \cdot 70, \mathrm{df}=1$, $P<0 \cdot 001)$. Both $\mathrm{ADH} 2 * 1 /{ }^{*} 2$ genotype, and high alcohol sensitivity, jointly predicted increased probability that a male twin would be from a concordant unaffected pair $(\mathrm{OR}=$ $7 \cdot 67,95 \% \mathrm{CI}=1 \cdot 16-50 \cdot 8 ; \mathrm{OR}=14 \cdot 47,95 \%$ $\mathrm{CI}=3 \cdot 18-65 \cdot 8)$.

\section{Bivariate genetic analyses}

Finally, in Table 5 parameter estimates obtained when a bivariate genetic model was fitted to alcohol dependence symptom count and alcohol sensitivity score data (ignoring the sensitivity scores of female twins) are summarized. A significant genetic correlation was indeed confirmed, albeit with a wide confidence interval $(0.72,95 \%$ CI $0.34-1 \cdot 00)$. In contrast, the estimated non-shared environmental correlation was much weaker (0.04).

\section{DISCUSSION}

To our knowledge, this represents the first report in which the possible mediational role of differences in alcohol sensitivity in the inheritance of alcoholism has been examined using the powerful twin study design, in women as well as men, and within the framework of a broader survey of genetic and environmental contributions to alcohol dependence risk. We also addressed for the first time the generalizability to the general population of findings from an alcohol challenge study, an important issue since volunteers for such research might be expected to be atypical of the general population. The study was unusual in that the twin pairs from which the alcohol challenge participants were drawn could be contrasted with other pairs from the Australian twin panel, providing direct information about the generalizability of findings. In the follow-up data presented here. in men, no differences in rates of psychopathology or heavy drinking between challenge study volunteers and other twin panel members were found, providing a rare (and possibly unique) example of a large-sample alcohol challenge study conducted on a broadly representative sample. In women, in contrast, alcohol challenge participants included a higher than expected proportion of heavy drinkers, and of drinkers with a history of alcohol dependence, presumably because women who were light drinkers at baseline were reluctant to volunteer for a study involving alcohol administration.

Previous analyses of data from the Australian alcohol challenge sample have shown significant heritability of various individual measures of alcohol sensitivity (Martin et al. $1985 a, b$; Heath \& Martin, 1992). Here, we were able to confirm significant heritability for a new composite measure (derived by principal components analysis of subjective intoxication and static ataxia scores), with genetic factors estimated to account for approximately $60 \%$ of the variance in sensitivity scores. We were also able to show, using data-weighting to correct for any selection 
bias effects (Heath et al. 1998), that the overrepresentation of heavy drinkers among the female alcohol challenge participants was not inflating this heritability estimate; the estimate was actually increased to $79 \%$ in women (but unchanged in men) in weighted analyses. We found no evidence for significant associations of alcohol sensitivity score with known genetic polymorphisms at the alcohol dehydrogenase $\mathrm{ADH} 2$ and $\mathrm{ADH} 3$ loci, which had previously been demonstrated to be associated with differences in alcohol dependence risk in this sample (Whitfield et al. 1998). Equally, history of major depressive disorder, and history of childhood conduct disorder, while significantly heritable (Slutske et al. 1998; Bierut et al. 1999) and important phenotypic predictors of differences in alcohol dependence risk (Heath $e t$ al. $1997 b$ ) in this sample, were not associated with differences in alcohol sensitivity score. The mechanisms by which genetic differences in the composite alcohol sensitivity measure arise remain to be determined.

In men, we did find significant support in our retrospective analyses for the prospective finding reported by Shuckit \& Smith (1996), that differences in alcohol sensitivity were predictive of differences in alcohol dependence risk. Males with a history of alcohol dependence had significantly lower overall alcohol sensitivity scores, compared with males from twin pairs where neither twin had a history of alcohol dependence at interview follow-up, as well as lower scores on the component measures of subjective intoxication and body-sway. In the case of the overall sensitivity score and bodysway measures, these differences remained significant in unweighted analyses (and showed a similar trend in weighted analyses) even in conservative analyses, which controlled for baseline measures of alcohol consumption and alcohol problems. Whereas Schuckit \& Smith emphasized the association between low alcohol sensitivity and increased alcohol dependence risk, however, we found strongest evidence for a protective effect of high alcohol sensitivity. (In other words, while we found an association in the same direction as that reported by Schuckit \& Smith-low sensitivity predicting high risk, and vice versa - we were able to demonstrate a significant association most clearly in individuals scoring at the high end of distribution of alcohol sensitivity scores, whereas they found better prediction at the low end of the distribution.) Highly alcohol-sensitive males (scoring in the upper $25 \%$ of the distribution of alcohol sensitivity scores) had a lifetime risk of alcohol dependence that was less than one-twelfth the risk for individual scoring below the 26th percentile $(2.4 \%$ versus $31.9 \%)$ and a greatly increased risk of being from a concordant nondependent twin pair $(94.7 \%$ versus $51.9 \%)$. The association between high alcohol sensitivity and reduced alcohol dependence risk remained significant even when differences in baseline measures of alcohol consumption patterns and problems were controlled for. While no significant association was observed in women, the observed trend was in the same direction.

In support of the findings of Schuckit \& Smith, we did find a significant association in males between low alcohol sensitivity and increased genetic risk of alcohol dependence: non-alcoholic MZ co-twins of alcohol dependent twins had significantly lower alcohol sensitivity scores than twins from concordant nondependent pairs. Furthermore, the sensitivity scores of male non-dependent twins from discordant MZ pairs were no higher than those of alcohol dependent respondents (indeed the trend was for even lower scores). Alcohol sensitivity scores of non-alcoholic DZ co-twins of alcohol dependent twins were intermediate between those of twins from concordant non-alcoholic pairs, and those of alcoholic twins and the MZco-twins of alcoholic twins, differing from neither group significantly (Fig. 2). Thus, the hypothesis that genetically determined differences in alcohol sensitivity score contributed significantly to differences in alcohol dependence risk was supported in males, with an estimated genetic correlation of 0.72 obtained in model-fitting analyses. These effects again remained significant in unweighted analyses (with a similar trend in weighted analyses) when baseline consumption and problem measures were controlled for. There was a trend for $\mathrm{MZ}$ co-twins of alcohol dependent twins to be overrepresented in the lowest $25 \%$ of the distribution of alcohol sensitivity scores. However, this effect was less striking than the powerful association between high alcohol sensitivity and low alcoholism risk. Differences in experimental protocol, as well as the much broader inclusion 
criteria used in the Australian alcohol challenge study, may have led to better discrimination between individuals low on alcohol sensitivity in the Schuckit study, but better discrimination between individuals high on alcohol sensitivity in the current study.

Several limitations of this study need to be acknowledged. In contrast to the positive associations with co-twin's history of alcohol dependence, we found no association between reported parental alcoholism and alcohol sensitivity in males, and indeed an effect in the opposite direction in weighted analyses that controlled for baseline consumption patterns and alcohol problems. It is possible that differences in the operationalization of alcoholism account for this difference. Co-twin's history of alcohol dependence was assessed by direct personal interview. In contrast, because of low numbers, parental history of alcoholism was assigned on the basis of the response of one or both twins to a screening questions about paternal or maternal alcohol problems (Slutske et al. 1996). Thus, it is possible that this approach is identifying too many parents with only a mild history of alcohol misuse as 'alcoholic'. Unfortunately, given the small sample sizes in the alcohol challenge study, further breakdown of the positive parental cases is not feasible.

No evidence was found for an association between alcohol sensitivity and alcohol dependence risk in women: alcohol sensitivity scores were uncorrelated with personal or co-twin's history of alcohol dependence. It does not appear that either the relatively high dose of alcohol used, or the over-representation of women with a history of heavy drinking among those willing to volunteer for an alcohol challenge study, can explain this negative finding. Either interpretation would fail to account for the observed trend for parental history of alcoholism to be associated with decreased sensitivity to a challenge dose of alcohol in these women, albeit only weakly (the effect disappeared once baseline drinking history was controlled for). Most probably the lower prevalence of alcohol dependence in women compared to men has contributed to our inability to detect significant associations in women, since no deliberate attempt was made to oversample individuals at high familial risk. Stronger social influences on abstemious use of alcohol may also have occurred in the women; for this cohort of Australian males, regular alcohol use would have been normative.

Interpretation of these findings must also take into account several limitations of the research methods used in the original alcohol challenge protocol. Participants in the alcohol challenge study had a prior history of exposure to alcohol, so we cannot determine the extent to which differences in alcohol sensitivity measures were a consequence of differences in initial sensitivity to alcohol, or the effects of acute or chronic tolerance. The original study was conducted in 1979-81, and some of its procedures (particularly the assessment of static ataxia) would be considered primitive by the standards of contemporary research. The measure of subjective intoxication asked participants to use a rating scale in which the highest point was 'the most drunk they had ever been', thus implicitly encouraging comparisons with their prior drinking experience. Whether this measure is more appropriately viewed as a measure of alcohol sensitivity, or of prior drinking experience is thus debatable, although its high correlations with static ataxia measures suggests that it is at least in part functioning as a sensitivity measure. A baseline measure of maximum 1-day alcohol consumption would have been desirable to control for possible differences in alcohol exposure.

No attempt was made to oversample subjects with a parental history of alcoholism or otherwise considered to be at risk for the future development of alcohol problems. While this is advantageous from the viewpoint of the representativeness of the sample, it is associated with an inevitable loss of statistical power, compared to studies which have over sampled individuals from high-risk backgrounds (Schuckit \& Smith, 1996). Finally, no subject exclusion criteria were used in the original study. This is associated with inevitable difficulties of interpretation, since some participants will have been heavy or problem drinkers at the time of the original alcohol challenge study, and we cannot exclude the possibility that the baseline measures of alcohol consumption and problem drinking failed to detect some cases with a history of excessive alcohol use. Despite these limitations, the positive findings that emerged, and in particular the remarkably reduced lifetime 
rate of alcohol dependence in Australian males falling in the highest $25 \%$ of the distribution of alcohol sensitivity scores, suggest that further investigation of the effect on alcohol dependence of genetically determined differences in response to alcohol, using a more efficient sampling design (i.e. oversampling individuals at high and very low genetic risk), and updated methods, is likely to be productive.

This work was supported, in varying percentages, by NIH grants AA07535, AA07728 and AA10249 (to A.C.H), DA00272 (to P.A.F.M.), post-doctoral training grants DA07261, MH17104 and MH14677, as well as grants from the Australian National Health and Medical Research Council (to N.G.M. and J.B.W.), the Australian Associated Brewers (to M.P.D.) and the US Alcohol Beverage Medical Research Foundation (to P.A.F.M.).

\section{REFERENCES}

Bauer, L. O. \& Hasselbrock, V. M. (1993). EEG, autonomic, and subjective correlates of the risk for alcoholism: an examination of the effects of anti-social personality disorder and a family history of alcoholism. Journal of Studies on Alcohol 54, 577-589.

Behar, D., Berg, C., Rapoport, J. L., Nelson, W., Linnoila, M. Cohen, M., Bozevich, C. \& Marshall, T. (1983). Behavioral and physiological effects of ethanol in high-risk and control children a pilot study. Alcoholism: Clinical and Experimental Research 7, $404-410$.

Bierut, L. J., Heath, A. C., Bucholz, K. K., Dinwiddie, S. H. Madden, P. A. F., Statham, D. J., Dunne, M. P. \& Martin, N. G. (1999). Major depressive disorder in a community-based twin sample: are there different genetic and environmental contributions for men and women. Archives of General Psychiatry 56, 557-563.

Bucholz, K. K., Cloninger, C. R., Dinwiddie, S. H., Hesselbrock V. M., Nurnberger, J. I., Reich, T., Schmidt, I. \& Schuckit, M. A (1994). A new, semi-structured psychiatric interview for use in genetic linkage studies: a report of the reliability of the SSAGA Journal of Studies on Alcohol 55, 149-158.

Cadoret, R. J., Cain, C. A., Troughton, E. \& Heywood, E. (1985) Alcoholism and antisocial personality. Interrelationships, genetic and environmental factors. Archives of General Psychiatry 42. 161-167.

Cadoret, R. J., Troughton, E. \& O'Gorman, T. W. (1987). Genetic and environmental factors in alcohol abuse and antisocia personality. Journal of Studies on Alcohol 48, 1-8.

Crowe. R. R. (1974). An adoption study of antisocial personality. Archives of General Psychiatry 31, 785-791.

Efron, B. \& Tibshirani, R. (1986). Bootstrap methods for standard errors, confidence intervals, and other measures of statistical accuracy. Statistical Science 1, 54-77.

Goodwin. D. W., Schulsinger, F., Hermansen, L., Guze, S. B. \& Winokur, G. (1973). Alcohol problems in adoptees raised apart from alcoholic biological parents. Archives of General Psychiatr. 28. 238-243.

Grove. W. M., Eckert, E. D., Heston, L., Bouchard, T. J. Jr., Segal, N. \& Lykken, D. T. (1990). Heritability of substance abuse and antisocial behavior: a study of monozygotic twins reared apart. Biological Psychiatry 27. 1293-1304.

Heath. A. C. (1995). Genetic influences on alcoholism risk? A review of adoption and twin studies. Alcohol Health and Research World 19. $166-171$
Heath, A. C. \& Martin, N. G. (1992). Genetic differences in psychomotor performance decrement after alcohol: a multivariate analysis. Journal of Studies on Alcohol 53, 262-271.

Heath, A. C., Slutske, W. S. \& Madden, P. A. F. (1997a). Gender differences in the genetic contribution to alcoholism risk and to alcohol consumption patterns. In Gender and Alcohol (ed. R. W. Wilsnack and S. C. Wilsnack), pp. 114-149. Rutgers University Press: Rutgers, NJ.

Heath, A. C., Bucholz, K. K., Madden, P. A. F., Dinwiddie, S. H., Slutske, W. S., Bierut, L. J., Statham, D. J., Dunne, M. P. Whitfield, J. \& Martin, N. G. (1997b). Genetic and environmental contributions to alcohol dependence risk in a national twin sample: consistency of findings in women and men. Psychological Medicine 27, 1381-1396.

Heath, A. C., Madden, P. A. F. \& Martin, N. G. (1998). Assessing the effects of cooperation bias and attrition in behavioral genetic research using data-weighting. Behavior Genetics 28. 415-427.

Hegedus, A. M., Tarter, R. E., Hill, S. Y., Jacob, T. \& Winsten, N. E. (1984). Static ataxia: a possible marker for alcoholism. Alcoholism: Clinical and Experimental Research 8, 580-582.

Jardine, R., Martin, N. G. \& Henderson, A. S. (1984). Genetic covariation between neuroticism and the symptoms of anxiety and depression. Genetic Epidemiology 1, 89-107.

Kendler, K. S., Heath, A. C., Martin, N. G. \& Eaves, L. J. (1986) Symptoms of anxiety and depression in a volunteer twin population: the etiologic role of genetic and environmental factors. Archives of General Psychiatry 43, 213-221.

Kendler, K. S., Heath, A. C., Neale, M. C., Kessler, R. C. \& Eaves, L. J. (1993). Alcoholism and major depression in women: a twin study of the causes of comorbidity. Archives of General Psychiatry 500, 690-698.

Kendler, K. S., Walters, E. E., Neale, M. C., Kessler, R. C., Heath. A. C. \& Eaves, L. J. (1995). The structure of the genetic and environmental risk factors for six major psychiatric disorders in women: phobia, generalized anxiety disorder, panic disorder. bulimia, major depression and alcoholism. Archives of General Psychiatry 52, 374-383

Kessler, R. C., Nelson, C. B., McGonalge, K. A., Edlund. M. J. Frank, R. G. \& Leaf, P. J. (1996). The epidemiology of cooccurring addictive and mental disorders; implications for prevention and service utilization. American Journal of Orthopsychiatry 66, 17-31.

Lex, B. W., Lukas, S. E., Greenwald, N. E. \& Mendelson. J. H (1988). Alcohol-induced changes in body sway in women at risk for alcoholism: a pilot study. Journal of Studies on Alcohol 49. 346-356

Lipscomb, T. R., Carpenter, J. A. \& Nathan, P. E. (1979). Static ataxia: a predictor of alcoholism? British Journal of Addictions 74 289-294.

Long, J. C., Knowler, W. C., Hanson. R. L., Robin, R. W., Urbanek M., Moore, E., Bennett, P. H. \& Goldman, D. (1998). Evidence for genetic linkage to alcohol dependence on chromosomes 4 and 11 from an autosome-wide scan in an American Indian population. American Journal of Medical Genetics (Neuropsychiatric Genetics) 81, 216-221.

McCaul, M. E., Turkkan. J. S.. Svikis. D. S. \& Bigelow. G. E. (1991) Alcohol and secobarbital effects as a function of familial alcoholism: extended intoxication and increased withdrawal effects. Alcoholism: Clinical and Experimental Research 15.9+101.

McGue. M. (1994). Genes, environment and the etiology of alcoholism. In The Development of Alcohol Problems: Exploring the Biopsychosocial Matrix of Risk (ed. R. Zucker. G. Boyd and J. Howard). pp. 1-4. US Department of Health and Human Services: Rockville. MD

Martin, N. G., Perl, J., Oakeshott. J. G., Gibson, J. B. Starmer. G. A. \& Wilks, A. V. (1985a). A twin study of ethanol metabolism. Behavior Genetics 15. 93-109.

Martin. N. G.. Oakeshott. J. G.. Gibson. J. B.. Starmer. G. A.. Perl J. \& Wilks. A. V. (1985b). A twin study of psychomotor and physiological responses to an acute dose of alcohol. Behavior Genetics 15, 305-347. 
Nagoshi, C. T. \& Wilson, J. R. (1987). Influence of family alcoholism history on alcohol metabolism, sensitivity, and tolerance. $A l-$ coholism: Clinical and Experimental Research 11, 392-398.

Neale, M. C. (1998). Mx: Statistical Modeling. Department of Psychiatry, Virginia Commonwealth University: Richmond, VA.

Neale, M. C. \& Martin, N. G. (1989). The effects of age, sex, and genotype on self-report drunkenness following a challenge dose of alcohol. Behavior Genetics 19, 63-78.

Neale, M. C. \& Cardon, L. R. (1992). Methodology for Genetic Studies of Twins and Families, NATO ASI Series. Kluwer Academic Publishers: Dordrecht, The Netherlands.

O'Malley, S. S. \& Maisto, S. A. (1985). Effects of family drinking history and expectancies on responses to alcohol in men. Journal of Studies on Alcohol 46, 289-297.

Pickens, R. W., Svikis, D. S. \& LaBuda, M. C. (1995). Common genetic mechanisms in alcohol, drug and mental disorder comorbidity. Drug Alcohol Dependence 39, 129-138.

Pollock, V. E. (1992). Meta-analysis of subjective sensitivity to alcohol in sons of alcoholics. American Journal of Psychiatry 149 1534-1538.

Regier, D. A., Farmer, M. E., Rae, D. S., Locke, B. Z., Keith, S. J. Judd, L. L. \& Goodwin, F. K. (1990). Comorbidity of mental disorders with alcohol and other drug abuse: results from the Epidemiologic Catchment Area (ECA) study. Journal of the American Medical Association 264, 2511-2518.

Reich, T., Edenberg, H. J., Goate, A., Williams, J. T., Rice, J. P., van Eerdewegh, P., Foroud, T., Hesselbrock, V., Schuckit, M. A Bucholz, K., Projesz, B., Li, T.-K., Conneally, M., Nurnberger, J. Tischfield, J. A., Crowe, R. R., Cloninger, C. R., Wu, W., Shears, S., Carr, K., Crose, C., Willig, C. \& Begleiter, H. (1998). Genomewide search for genes affecting the risk for alcohol dependence. American Journal of Medical Genetics (Neuropsychiatric Genetics) 81, 207-215.

Rosenbaum, P. R. \& Rubin, D. B. (1983). The central role of the propensity score in observational studies for causal effects. Biometrika 70, 41-55.

SAS Institute Inc. (1990). SAS/STAT User's Guide, Version 6, Fourth Edition. SAS Institute, Inc.: Cary, NC.

Schuckit, M. A. (1984a). Subjective responses to alcohol in sons of alcoholics and control subjects. Archives of General Psychiatry 41. $879-884$
Schuckit, M. A. $(1984 b)$. Differences in plasma cortisol after ingestion of ethanol in sons of alcoholics and controls: preliminary results. Journal of Clinical Psychiatry 45, 374-376.

Schuckit, M. A. (1985). Ethanol-induced changes in body sway in men at high alcoholism risk. Archives of General Psychiatry 42 , 375-379.

Schuckit, M. A. \& Smith, T. (1996). An 8-year follow-up of 450 sons of alcoholic and control subjects. Archives of General Psychiatry 53, 202-210.

Schulsinger, F. (1972). Psychopathy: heredity and environment. International Journal of Mental Health 1, 190-206.

Slutske, W. S., Heath, A. C., Madden, P. A. F., Bucholz, K. K. Dinwiddie, S. H., Dunne, M. P., Statham, D. J. \& Martin, N. G. (1996). Reliability and reporting biases for perceived parental history of alcohol problems: agreement between twins and differences between discordant pairs. Journal of Studies on Alcoho 57, 387-395.

Slutske, W. S., Heath, A. C., Dinwiddie, S. H., Madden, P. A. F. Bucholz, K. K., Dunne, M. P., Statham, D. J. \& Martin, N. G. (1998). Common genetic risk factors for conduct disorder and alcohol dependence. Journal of Abnormal Psychology 107, 363-374.

Stata Corp. (1997). Stata Statistical Software: Release 5.0. Stata Corporation: College Station, TX

True, W. R., Heath, A. C., Scherrer, J. F., Xian, H., Lin, N., Eisen, S. A., Lyons, M. J., Goldberg, J. \& Tsuang, M. (1999). Interrelationship of the genetic and environmental influences on conduct disorder, alcohol and marijuana dependence symptoms. American Journal of Medical Genetics (Neuropsychiatric Genetics) (in the press)

von Wartburg, J. P., Gennari, K., Muellener, D. \& Wermuth. B. (1988). Determination of the genotype of human class I alcohol dehydrogenase. In Biomedical and Social Aspects of Alcohol and Alcoholism (ed. K. Kuriyama, A. Takada and H. Ishii), pp. 35-38. Elsevier Science: New York.

Whitfield, J. B., Nightingale, B. N., Bucholz, K. K., Madden. P. A. F., Heath, A. C. \& Martin, N. G. (1998). ADH genotypes and alcohol use and dependence in Europeans. Alcoholism: Clinical and Experimental Research 22, 1463-1469.

Xu, Y., Carr, L. G., Bosron, W. F., Li, T.-K. \& Edenberg. H. J. (1988). Genotyping of human alcohol dehydrogenases at the $\mathrm{ADH} 2$ and $\mathrm{ADH} 3$ loci following DNA sequence amplification. Genomics 2, 209-214. 